14-16 May, 2021

Paris, France $1^{\text {th }}$ International Conference on

Humanities, Psychology \& Social Sciences

\title{
Some Transformations in the Linguistic Consciousness
}

\author{
${ }^{1}$ Maia Chkheidze, ${ }^{2}$ Revaz Tabatadze \\ ${ }^{1,2}$ the University of Georgia
}

\begin{abstract}
Any major transformation occurring in the world causes changes in the regulation of human activities. Ideals and principles of perception, activities, values, and spiritual orientation are variable in time. The regulators we need to perform in the universe are historically preconditioned - they imply a constant change of the world view and its subjects, they give impetus to values, hierarchy and thinking paradigms.

The research of the linguistic consciousness is implemented by applying the method of the free associative experiment aimed at revealing informants' (English and Georgian speakers) associates-reactions to certain stimuli. The frequency ratios of reactions have been defined and the specifics of the core-periphery relationship has been identified in the associative fields.

The procedure of the free associative experiment revealed: a. the similarities and differences between the linguistic world view depicted in the dictionaries; $b$. the specifics of the perception of certain concepts by modern native speakers; c. the character of the transformation of the linguistic world view according to the new extra linguistic realities.

The comparison of the lexical-semantic and associative fields has been made. The mentioned entities have been constructed by applying the principle of significance. According to the mentioned principle, each element of the field has been included in the system due to its meaning and significance determined on the basis of the system as a whole.
\end{abstract}

Keywords: Associative Field; Free Associative Experiment; Linguistic Consciousness; Linguistic Worldview; Extra Linguistic Realities.

\section{INTRODUCTION}

Our existence starts with the creation of the world view. We need some special symbolic structures (language, mythology, religion, arts, and science) to orientate in the universe. These structures regulate our existence in the universe; their unity creates the fundamental and global view that helps us to perform in the universe. Any major transformation causes changes in the regulation of human activities - ideals and principles of perception, activities, values and spiritual orientation. These regulators are variable in time and space. Being historically preconditioned, world view implies a constant change of the world view and its subjects. A world view gives impetus to values, hierarchy and thinking paradigms. From the perspective 
14-16 May, 2021

Paris, France $12^{\text {th }}$ International Conference on Humanities, Psychology \& Social Sciences

of the anthropocentric paradigm a man perceives the universe, in other words, a man creates anthropocentric centre in his consciousness which determines his spiritual essence, intentions of his actions and hierarchy of values.

The indispensable condition of human existence is the rationalization of the world. The process of rationalization of the world implies the process of thinking about the threats of the universe and developing the mechanisms to tackle them.

Each language possesses its own style of conceptualization. Accordingly, each language creates its own world view through which a speaker organizes the content of the expression (Corson, 1995).

Language is a means of forming human knowledge on the universe. The sum total of the knowledge, accumulated through linguistic forms, is the phenomenon called "lingual representation of the world".

How to think and talk about the impact the corona virus is having on our lives? How to deal with the epidemic explosion of new associations and neologisms? - The thing is that, these novelties help us make sense of our new world and reveal the specifics of the linguistic consciousness of man.

Let's see how the linguistic creativity manifests itself in times of serious crisis!

World War II gave us "radar" (radio detection and ranging), from Vietnam we got both "clusterfuck" (a mishandled or disorganised situation) and "fragging" (the deliberate killing of an unpopular member of one's own fighting unit, from the shortening of fragmentation grenade).

Lerer wrote, "War always changes language. It brings in new words, changes attitudes, [and] shifts dialects." (Lerer, 2007).

Wilfred Funk, author of "Word Origins and Their Romantic Stories," estimated that for each year the United States was involved in World War II, we added more than 6,000 words to the American vocabulary (Funk, 1950).

In 2011, author and slang expert Paul Dickson produced the third edition of his book "War Slang: American Fighting Words and Phrases Since the Civil War," in which he shows how language mirrors the unique experience of each conflict from the Civil War through the Iraq War (Dickson, 2003).

The scope of lexical innovation in relation to coronavirus is unprecedented - coronavirus neologisms are intensively being coined: "covidiot" (someone ignoring public health advice), "covideo party"(online parties via Zoom or Skype), and "covexit" (the strategy for exiting lockdown), "blursday" (an unspecified day because of lockdown's disorientating effect on time), to "zoombombing" (hijacking a Zoom videocall). "WFH" (working from home) and "quaranteams" (online teams created during lockdown), infodemic (information + epidemic. 
14-16 May, 2021

Paris, France $12^{\text {th }}$ International Conference on Humanities, Psychology \& Social Sciences

The spread of information, some of it not so substantiated, contributing to anxiety or speculation, linked to a crisis or a controversy), coronabesity (corona + obesity), coronarelationship (a temporary relationship with somebody one knows maintained because one does not want to stay alone during the quarantine).

In 1950, prior to the Korean War, novelist Robert C. Ruark wrote in a syndicated newspaper column, "That seems to be one of the nicer things about war - it enriches the language so."

The same can be said about the corona virus: "That seems to be one of the nicer things about the corona virus - it enriches the language so".

\section{Methodology}

The research of the linguistic consciousness is implemented by applying the method of the free associative experiment aimed at revealing informants' (English and Georgian speakers) associates-reactions to certain stimuli (Deese, 1965). The experiment covered the informants of various specialties, the gender sign was in equal proportions.

Nearly 700 associative connections between the word-stimulus (life) and associates-reactions to it obtained through the free associative experiment have been analysed in the article. The frequency ratios of reactions have been defined and the specifics of the core-periphery relationship has been identified. The comparison of the lexical-semantic and associative fields of "life" has been made.

The procedure of the free associative experiment revealed: a. the similarities and differences between the linguistic world view depicted in the dictionaries; $b$. the specifics of the perception of the concepts of "life" by modern native speakers; c. the character of the transformation of the linguistic world view according to the new extra linguistic realities.

The lexical-semantic and associative fields of "life" have been constructed by applying the principle of significance by Ferdinand de Saussure. According to the mentioned principle, each element of the field possesses meaning and significance simultaneously, in other words, each element of the field is included in the system due to its meaning and significance determined on the basis of the system as a whole (Lehrer \& Kittay, 1992).

So, we constructed the lexical-semantic field of "life" considering that:

1. The meaning should be derived from the regularity of the entire structure;

2. Each element, being the member of the value system, should be determined by other elements, in other words, the system should determine its elements;

3. The field should be regulated by the law of organic separation;

4. The members of the organic entity should affect each other. 
14-16 May, 2021

Paris, France $12^{\text {th }}$ International Conference on Humanities, Psychology \& Social Sciences

\section{Body of paper}

By applying the principle of significance, the lexical-semantic and associative fields of "life" have been segmented into the core and periphery. The mentioned type of segmentation implies indicating the rank of every element in the hierarchy and revealing the specifics of the core and periphery of the linguistic consciousness.

To conduct the research the descriptive method to characterize the phenomena of language at this stage of its development has been used. The comparative method helped to determine general and specific features of the English and the Georgian languages. The statistical method has been applied to reveal the most frequent associates existing in the linguistic consciousness of native speakers. The experimental method, in particular, the method of the free associative experiment has been considered to be an effective method to study the linguistic consciousness. In the free associative experiment, the stimulus "life" called up a number of unique and universal associations of the language speakers. On the basis of the reactions of native speakers to the stimulus "life" the associative field of "life" has been modelled. To construct the lexicalsemantic field of "life" the componential analysis of the semantic structure of the field elements has been conducted.

\section{Results and discussion}

The analysis of the lexicographic definitions of "life" revealed four lexical-semantic variants:

1. A state of organisms characterized by the capacity to perform certain functional activities, including, breath, growth, reproduction, metabolism, reaction to stimuli, that makes people, animals, and plants different from objects, substances, and things that are dead;

2. The interval of time between somebody'sbirth and their death; or the period for which a machine or organization lasts;

3. The events and experiences that happen to people while they are alive; the things that people do and experience that are characteristic of a particular time, place, or group of people;

4. A book which tells the story of someone's life, written by someone else or by that particular person, i.e. biography/autobiography.

Figure 1: I lexical-semantic variant and its elements

\begin{tabular}{|l|l|}
\hline \multicolumn{2}{|c|}{ I lexical-semantic variant } \\
\hline & blood; body; animal; man; being; person; activity; \\
& existence; creature; growth; impulse; viability; \\
& organism; mortal; flesh; vitality; breath; wild; \\
& woman; consciousness; symbiosis; subsistence; \\
& human; metabolism. \\
\hline
\end{tabular}

Figure 2: Associative dimension of the first lexical-semantic variant and its associates 
14-16 May, 2021

Paris, France $12^{\text {th }}$ International Conference on Humanities, Psychology \& Social Sciences

\begin{tabular}{|l|l|}
\hline \multicolumn{2}{|c|}{ Associative dimension of the first lexical-semantic variant } \\
\hline & man; person; feel; woman; heart; body; being; \\
& animal; real; human; breath; warm; skin; blood; \\
& human being; presence; alive; physical; flesh; \\
& mental; consciousness; natural; activity; energy; \\
& unconscious; creature; existence; survival; growth; \\
& function; alert; dynamic; vitality; organ; mortality. \\
\hline
\end{tabular}

Figure 3: II lexical-semantic variant and its elements

\begin{tabular}{|l|l|}
\hline \multicolumn{2}{|c|}{ II lexical-semantic variant } \\
\hline & man; person; feel; woman; heart; body; being; \\
& animal; real; human; breath; warm; skin; blood; \\
& human being; presence; alive; physical; flesh; \\
& mental; consciousness; natural; activity; energy; \\
& unconscious; creature; existence; survival; growth; \\
& function; alert; dynamic; vitality; organ; mortality. \\
\hline
\end{tabular}

Figure 4: Associative dimension of the second lexical-semantic variant and its associates

\begin{tabular}{|l|l|}
\hline \multicolumn{2}{|c|}{ Associative dimension of the second lexical-semantic variant } \\
\hline & $\begin{array}{l}\text { time; hour; pass; day; course; age; moment; start; } \\
\text { spend; go on; future; stage; period; daily; existence; } \\
\text { episode; lifetime; duration; lifelong; perpetual; } \\
\text { continuance; span; endurance. }\end{array}$ \\
\hline Associates &
\end{tabular}

Figure 5: III lexical-semantic variant and its elements

\begin{tabular}{|l|l|}
\hline \multicolumn{2}{|c|}{ III lexical-semantic variant } \\
\hline Elements & $\begin{array}{l}\text { way of life; world; activity; conduct; career; } \\
\text { personality; behavior; experience; situation; lifestyle; } \\
\text { culture; civilization; society. }\end{array}$ \\
\hline
\end{tabular}

Figure 6: Associative dimension of the third lexical-semantic variant and its associates

\begin{tabular}{|l|l|}
\hline \multicolumn{2}{|c|}{ Associative dimension of the third lexical-semantic variant } \\
\hline & $\begin{array}{l}\text { work; world; full; relationship; empty; marriage; } \\
\text { experience; event; college; situation; ordinary; } \\
\text { Associates }\end{array}$ \\
$\begin{array}{l}\text { private; plan; career; activity; torture; culture; } \\
\text { society; behavior; lonely; domestic; location; }\end{array}$ \\
\hline
\end{tabular}


14-16 May, 2021

Paris, France $12^{\text {th }}$ International Conference on Humanities, Psychology \& Social Sciences

development; social life; comfort zone; conduct; personality.

Figure 7: IV lexical-semantic variant and its elements

\begin{tabular}{|l|l|}
\hline \multicolumn{2}{|c|}{ IV lexical-semantic variant } \\
\hline Elements & $\begin{array}{l}\text { history; life story; confession; diary; bio; profile; } \\
\text { journal. }\end{array}$ \\
\hline
\end{tabular}

Figure 8: Associative dimension of the fourth lexical-semantic variant and its associates

\begin{tabular}{|l|l|}
\hline \multicolumn{2}{|c|}{ Associative dimension of the fourth lexical-semantic variant } \\
\hline & $\begin{array}{l}\text { story; history; write; character; film; describe; life } \\
\text { story; confession; diary; novel; drama; page; photo } \\
\text { album; biography; autobiography. }\end{array}$ \\
\hline
\end{tabular}

The first and second lexical-semantic variants create the core of the lexical-semantic field of "life", while the third and fourth lexical-semantic variants mould the field periphery.

The structure of the lexical-semantic field of "life" is gradual. The mentioned type of structure is created by the dynamic word-identificator of the field. The word-identificator is dynamic if it changes its value, i.e. the status of the main components of meaning in the semantic structure of some field elements. Dynamism of the word-identificator conditions the variety of semantic relations, in other words, inequality of the distance between the word-identificator and different elements of the field which, in its tern, results in graduality of the structure, more precisely, in the existence in the field structure of dominant segments (with respect to one another and to the word-identificator) - core and periphery.

The associative dimensions of the first and second lexical-semantic variants are located in the core of the associative field of "life", while the associative dimensions of the third and fourth lexical-semantic variants present the field periphery.

The structure of the associative field of "life" is gradual. The mentioned type of structure is created by the dynamic word-stimulus. The word-stimulus is dynamic if it changes its value i.e. the status of the main stimulus in the associative structure of some associates-reactions. Dynamism of the word-stimulus conditions inequality of the distance between the wordstimulus and different associates-reactions of the field which, in its tern, results in graduality of the structure, more precisely, in the existence in the field structure of dominant segments (with respect to one another and to the word-stimulus) - core and periphery.

The mentioned type of segmentation implies indicating the rank of every element in the hierarchy and revealing the specifics of the core and periphery of the linguistic consciousness. 
14-16 May, 2021

Paris, France $12^{\text {th }}$ International Conference on Humanities, Psychology \& Social Sciences

The core of the associative field is presented by the associate-reactions that come first to the word-stimulus.

The analysis of the core of the associative field of "life" constructed by us in February 2021 revealed that the mentioned segment of the field comprises the elements of the core of the associative field of "death". These elements are: Covid-19; fear; danger; epidemic; death; dead; end; doom; fatality; ruin; loss of life; departure from life; finish; cessation; termination; collapse etc.

The intersection of the cores of the associative fields of "life" and "death" has been caused by the vagueness of the contours of the associative fields of "life" and "death".

To sum up, the continuum of the associative field of "life" is variable in time - new realities have shaped and transformed the continuum of the associative field. We interpret the transformation occurring in the continuum of the associative field of "life" as the result of the continuous (permanent) reproduction (interpretation and reinterpretation) of the reality.

The analysis of the associative and lexical-semantic fields of "life" in the English and Georgian languages revealed the integral and differential signs of their structure. The elements of the lexical-semantic field belong to the association field structure, while the reactions that have no direct connection to the semantic stimulus are not integrated into the lexical-semantic field. The associative field is always more voluminous than the lexical-semantic field. The associative field comprises all the reactions-associates allowing identification of the essential markers of the native speakers' world view.

The associative field reveals the specificity of a respondent's relation to a word-stimulus, while the semantic field describes the relation of a given word to other words.

The analysis of the material of the free associative experiment revealed that the concept of "life" perceived and interpreted by the respondents has been manifested in the cause-effect, temporal and spatial relations.

\section{Conclusion}

The essential part of the associative and lexical-semantic fields of "life" in English and Georgian is focused on the sphere of linguistic consciousness and cognitive perception.

The research of linguistic consciousness implemented by the method of the free associative experiment identified the similarities and differences between the linguistic worldview depicted in the dictionaries, revealed the specifics of the perception of the concept of "life" by 
14-16 May, 2021

Paris, France $12^{\text {th }}$ International Conference on Humanities, Psychology \& Social Sciences

native speakers and determined the character of the transformation of the linguistic worldview according to the new extra linguistic realities.

Novelties are triggered by social and political events especially in times of war and natural disasters. However, the case for the corona virus is different, since associations and neologisms generated by the corona virus are of global meaning.

Neologisms are coined and associations are created to fill a void created by perception, demonstrating the influence of perception over language. In turn, neologisms and associations influence the perception of language bearers.

The analysis of the reactions to the stimulus "life" showed that the associative fields of "life" constructed in the English and Georgian languages coincide in general.

The continuum of the core segment of the associative field of "life" intersects with the continuum of the core segment of the associative field of "death".

We believe that this intersection is a temporary phenomenon!

\section{References}

Corson, D. (1995) Worldview, Cultural Values and Discourse Norms: The Cycle of Cultural Reproduction." International Journal of Intercultural Relations 19.

Deese, J. (1965). The structure of associations in language and thought. Baltimore: Johns Hopkins Press.

Dickson, P. (2003). War Slang: American Fighting Words \& Phrases Since the Civil War. Brassey's, Inc.

Funk, W. (1950). Word origins and their romantic stories. New York: Funk \& Wagnalls. Lehrer A., and Kittay E. F. (1992). Frames, Fields, and Contrasts. Hillsdale, NJ: Erlbaum.

Lerer, S. (2007). Inventing English: A Portable History of the Language. Columbia University Press: New-York 